PS-267 CHANGES IN NUTRITIONAL MANAGEMENT AMONG VERY LOW BIRTH WEIGHT INFANTS BETWEEN 2010 AND 2013 - WHAT WE WERE BE ABLE TO IMPROVE

M Kesiak, P Kicinski, T Talar, M Polinski, E Gulczynska. Neonatology, Polish Mother's Memorial Hospital - Research Institute, Lodz, Poland

\subsection{6/archdischild-2014-307384.567}

Background The feeding scheme of premature newborns changed in recent years. The latest recommendations emphasise the intensification both of parenteral and enteral nutrition from the first days of life.

Methods We compared two groups of VLBW newborns born in our institution in 2010 and 2013. We analysed how the changes of our nutritional treatment influenced chosen parameters in both groups of newborns. Changes included: more intensive full TPN from first hours of life, earlier enteral nutrition (EN), faster increasing of EN, less restrictive fluid policy during first week of life, supplementation of proteins during EN and more exact growth charts.

Results The demographic parameters of both groups were very similar. In 2013 compared to 2010 we found smaller average weight loss after birth $(6,4 \%$ vs $9,7 \% ; \mathrm{p}<0,05)$, faster return to birth weight ( 8 vs 12,5 days; $\mathrm{p}<0,01$ ) and higher average daily weight gain $(21,5$ vs $19,6 \mathrm{~g} /$ day; $\mathrm{p}<0,05)$. The mean duration of TPN use was slightly shorter (18 vs 20 days; NS). Extra uterine growth restriction at the time of discharge decreased significantly but still was $43,3 \%$ in 2013. Improvement has taken place mainly in the subgroup of ELBW infants. The incidence of severe NEC declined from 10\% in 2010 to 6,4\% in 2013.

Conclusions We revealed that our changes caused improvement of nutrition and brought beneficial effect on the growing parameters of our premature newborns without increasing the incidence of NEC.

\section{PS-268 STOOL CHARACTERISTICS AND GASTROINTESTINAL TOLERANCE OF CHINESE INFANTS FED TERM FORMULA CONTAINING INCREASED SN-2 PALMITATE AND OLIGOFRUCTOSE: AN OBSERVATIONAL STUDY}

${ }^{1} \mathrm{~K}$ Yerger, ${ }^{2} \mathrm{M} \mathrm{Mao},{ }^{3} \mathrm{~J} \mathrm{Ge},{ }^{1} \mathrm{R}$ Northington, ${ }^{1} \mathrm{M}$ Yao, ${ }^{1} \mathrm{~J}$ Nowacki, ${ }^{1} \mathrm{~N}$ Hays. ${ }^{1} \mathrm{Cl}$ inical Science, Nestlé Nutrition, King of Prussia PA, USA; ${ }^{2}$ Children's Healthcare Department, Chengdu Women's and Children's Central Hospital, Chengdu, China; ${ }^{3}$ Medical Department, Wyeth Nutritional (China) Company Ltd., Shanghai, China

\subsection{6/archdischild-2014-307384.568}

Background and aims Formula containing increased $s n-2$ palmitate with oligofructose $(s n-2+\mathrm{OF})$ may improve stool consistency. We hypothesised that hard and watery stool incidence among infants fed $\alpha$-lactalbumin-enriched formula with $s n$-2 + OF would be $\leq 2.5 \%$ (upper limit of $80 \%$ CI $<5.0 \%$ ).

Methods Healthy term infants $(n=440)$ aged $\sim 42$ days were enrolled in this 48-day study on their current feeding regimens: formula-fed $(n=142)$, HM-fed $(n=143)$, or mixed-fed $(n=$ 155). Stool consistency was assessed at 4 visits using a 3-day diary with validated 5 -point scale $(1=$ watery, $5=$ hard). Gastrointestinal (GI) tolerance was assessed using a validated questionnaire (score range $=13-65$; lower values indicate better tolerance).

Results Incidence of hard stools across visits ranged from $0.7 \%$ [80\% CI: $0.1-2.7]$ to $2.1 \%$ [0.8-4.6] for formula-fed infants, with incidence rates $\leq 0.8 \%$ in mixed-fed, and no hard stools reported in HM-fed groups. Incidence of watery stools ranged from $2.8 \%$ [1.2-5.4] to $5.0 \%$ [2.8-8.3] for formula-fed infants, which was lower than the incidence rates for mixed-fed $(\leq 8.2 \%)$ and HM-fed $(\leq 16.3 \%)$ groups. Stool consistency score ( 2 = runny, $3=$ mushy soft) of formula-fed infants (2.9) was higher than HM-fed infants (2.4-2.5; p

Conclusions Formula with $s n-2+\mathrm{OF}$ fed to Chinese infants results in soft stools and low incidence of hard and watery stools. Low GI tolerance scores indicate the formula is well tolerated.

\section{PS-269 EFFECT OF LONG TIME LOW TEMPERATURE (LTLT) PASTEURISATION AND LYOPHILYZATION ON PROTEINS CONTENT OF HUMAN MILK BANKING (HMB)}

${ }^{1} \mathrm{D}$ Lamireau, ${ }^{2} \mathrm{~L}$ Creppy, ${ }^{3} \mathrm{P}$ Martin, ${ }^{4} \mathrm{P}$ Perez, ${ }^{5} \mathrm{C}$ Billeaud. ${ }^{1}$ Lactarium Bordeaux-Marmande, CHU Bordeaux, Bordeaux, France; ${ }^{2}$ USMR CHU de Bordeaux, Interne de Santé Publique, Bordeaux, France; ${ }^{3}$ Equipe "Lait Génome And Santé », INRA Jouy-en-Josas, Jouy-enJosas, France; ${ }^{4}$ USMR, ISPED CHU Bordeaux, Bordeaux, France; ${ }^{5}$ CIC Pédiatrique Neonatology And Nutrition, CHU Bordeaux, Bordeaux, France

\subsection{6/archdischild-2014-307384.569}

Background Donor breast milk has been associated with slower growth in the early postnatal period. The macronutrient concentrations of human milk (HM) might be influenced by the various processes used in human milk banks (HMB). The (LTLT) pasteurisation was known to slightly decrease protein and fat content of HM, but the effect of lyophilization has not been described.

Aims To compare the protein composition between raw and LTLT-HM, and between LTLT-HM and lyophilized HM

Methods This was a prospective monocentre study on 22 independent HM batches. Total proteins were measured by 2-D Quant Kit and sIgA, Lysozyme, Lactoferrin by Elisa-kit in Raw/ LTLT/ lyophilized HM. Medians of protein concentrations were compared by Wilcoxon paired test.

Results

\begin{tabular}{lllll}
\multicolumn{2}{l}{ Abstract PS-269 Table 1} \\
\hline Proteins (g/l) & $\mathrm{n}$ & Median Raw & Median LTLT & $\mathbf{P}$ \\
Total Proteins & 22 & 11.63 & 9 & $<0.0001$ \\
slgA & 22 & 1.03 & 0.67 & $<0.0001$ \\
Lactoferrin & 22 & 2.01 & 0.30 & $<0.0001$ \\
Lysozyme & 22 & 0.58 & 0.47 & $<0.0001$ \\
\hline
\end{tabular}

\begin{tabular}{lllll}
\multicolumn{6}{l}{ Abstract PS-269 Table 2} \\
\hline Proteins (g/l) & $\mathbf{n}$ & Median LTLT & Median Lyophylization & $\mathbf{P}$ \\
Total Proteins & 18 & 9 & 9,41 & 0.1187 \\
slgA & 18 & 0.67 & 0.67 & 0.8811 \\
Lactoferrin & 18 & 0.30 & 0.30 & 0.2499 \\
Lysozyme & 16 & 0.47 & 0.47 & 0.9595 \\
\hline
\end{tabular}

Conclusion There was a significant decrease in total and immune proteins (sIgA, Lysozyme, Lactoferrin) between raw and LTLT-HM, which may explain less growth when LTLT-HM is used without fortifier, and less antiinfective properties. On the other hand, lyophilization did not further modify the content of total and immune proteins after pasteurisation.

Pasteurisation has got limitations as a process for preserving donor HM. Other techniques must be developed for decontaminating HM. 